\title{
Dietary Lipid and Postnatal Development. II. Palmityl Coenzyme A Oxidation in Heart and Liver
}

\author{
JUNE R. APRILLE(24) \\ Children's Service, Massachusetts General Hospital; Department of Pediatrics, Harvard Medical School; \\ Shriner's Burns Institute, Boston, Massachusetts, USA
}

\begin{abstract}
Extract
There is only indirect evidence to suggest that the sudden postpartum appearance of dietary lipid regulates the perinatal development of the enzyme pathways required for fatty acid oxidation. To test this idea directly, rabbit pups were maintained on diets containing lipid to equal either $14.2 \%$ (LF) or $77.6 \%$ (HF) of the total caloric intake. Palmityl coenzyme A oxidation rates in the presence of excess ADP and carnitine were measured polarographically in heart and liver homogenates. No significant difference in oxidation rates between $\mathrm{HF}$ and LF groups was observed even at 10 days of age. Palmityl coenzyme $A$ oxidation in both groups was carnitine dependent and was in general the same as that of mother-fed animals. Similarly, an evaluation of cytochrome oxidase activity and glutamate + malate-supported respiration in heart and liver homogenates revealed no difference attributable to diet.

To consider the possibility that fatty acid oxidation might be specifically increased or decreased over other mitochondrial respiratory activity as a function of diet, palmityl coenzyme $A$ oxidation rates were normalized with respect to glutamate + malate oxidation rates. A similar comparison was made relative to cytochrome oxidase activity. Still no differences were observed between HF and LF groups.

By studying the maximum rate of oxygen utilization in the presence of excess carnitine and palmityl-coenzyme $A$ we would have detected any change in a rate-limiting step for fatty acid oxidation beyond acyl activation. We must conclude, therefore, that large differences in the proportion of postnatal dietary lipid do not influence the cellular capacity to oxidize palmityl coenzyme A.
\end{abstract}

\section{Speculation}

We found no evidence to support the suggestion that the ability to oxidize long chain fatty acids is influenced by the amount of lipid in the postnatal diet. It seems likely that factors other than dietary lipid may be more important in regulating perinatal oxidative energy metabolism.

Neonatal life places large and urgent demands upon cellular energy metabolism. At birth, there is a sudden change in availability of energy-yielding substrates: maternal blood glucose is replaced by a high fat diet of milk. Besides a change in the potential source of energy, there is a demand for more energy; in addition to ongoing needs for growth and differentiation, there are new requirements for movement and heat production. Although liver glycogen stores are present at birth, these are rapidly depleted $(13,19)$. Once nursing commences, dietary lipid is a ready source of energy, but the capacity for fatty acid oxidation is deficient in the mammalian neonate $(4,7,10,18,20)$; rapid maturation of the enzymatic pathways for fatty acid oxidation (FAO) is suddenly essential to survival and normal development. Understanding the factors that control the enzyme activities required for FAO must therefore be considered an important facet of newborn management.

There is indirect evidence $(1,17)$ to support the suggestion $(17$, 18) that the sudden postpartum appearance of dietary lipid regulates the perinatal development of the pathways for FAO. Direct evidence is lacking because of inherent difficulties in varying the lipid content in the neonatal diet of laboratory animals. In order to provide a new approach to this question, we recently established a model in which the amount of dietary lipid could be controlled from birth to 10 days of age (3). In the model, rabbit pups were maintained on diets containing lipid to equal either $14.2 \%$ or $77.6 \%$ of the total caloric intake. We report here a comparison of these two groups with respect to maximum rates of palmityl coenzyme A oxidation in heart and liver as a first step to elucidating a possible modulating effect of lipid diet on FAO during the immediate postnatal period.

\section{METHODS}

\section{CARE AND FEEDING OF NEONATES}

New Zealand white rabbits were used in all experiments. Newborn littermates were maintained on high fat (HF) or low fat (LF) artificial diets as previously described (3). The LF diet provided approximately $14 \%$ of total calories as lipid, and the HF diet provided approximately $78 \%$ of the total calories as lipid.

\section{PREPARATION OF TISSUE HOMOGENATES}

Animals were killed and exsanguinated by decapitation. Whole homogenates of heart and liver of individual animals were prepared as noted previously (2).

\section{BIOCHEMICAL ASSAYS}

Glutamate + malate-supported respiratory activity and cytochrome oxidase were measured in homogenates by the polarographic technique described elsewhere (2). Maximum rates of fatty acid oxidation were also measured polarographically (18) with the following additions to the assay medium: homogenate $(1-3 \mathrm{mg}$ protein) followed successively by about $5 \mathrm{mg}$ fat-free (8) bovine serum albumin (BSA), $50 \mu \mathrm{g}$ palmityl coenzyme A (Pal-CoA), 300 $\mathrm{nmol} A \mathrm{AP}$, and $1 \mu \mathrm{mol} \mathrm{L}$-carnitine. All substrates were present in excess. Protein was measured by the method of Lowry et al. (11). Results were calculated as nanoatoms of oxygen utilized per min per mg protein.

\section{MATERIALS}

Crystalline BSA (fraction V), Pal-CoA, and ADP were all from Sigma Chemical Company. L-Carnitine was a gift from $\mathrm{Dr}$. Joseph Warshaw. 


\section{RESULTS}

\section{CARNITINE-DEPENDENT PAL-COA OXIDATION IN HOMOGENATES}

Direct recordings of oxygen utilization by homogenates from normal animals are shown in Figure 1 to illustrate that both ADP and L-carnitine were usually necessary for the expression of maximum rates of Pal-CoA oxidation. It is well established that carnitine is required for transfer of $\mathrm{Pal}-\mathrm{CoA}$ into the mitochondria via a palmitylcarnitine intermediate. Therefore, the significant oxidation rates observed before the addition of carnitine suggest that some endogenous carnitine is present (5). In preparing homogenates, endogenous carnitine levels were probably diluted to levels that are apparently rate limiting, since the addition of excess carnitine produced an increase in oxidation rates. This increase was usually greater for liver (Fig. 1a) than for heart (Fig. 1b), which may reflect higher endogenous carnitine levels in heart tissue. Others have reported higher carnitine levels in heart as compared with liver in piglets (5). It is also possible the carnitine levels required for maximum rates of $\mathrm{Pal}-\mathrm{CoA}$ oxidation are lower in heart homogenates as compared with liver.

\section{CELLULAR RESPIRATION IN ANIMALS FED HF AND LF DIETS}

We measured two other cellular respiratory functions, cytochrome oxidase activity and glutamate + malate-supported respiration, both of which have been used as indices of mitochondrial number (17). Both activities are thought to be proportional to the number of respiratory assemblies; oxygen utilization by intact mitochondria in the presence of glutamate + malate involves Krebs cycle enzymes as well.

An evaluation of cytochrome oxidase activity and glutamate + malate-supported respiration in hearts and livers of HF and LF animals (Tables 1 and 2) revealed no difference attributable to diet. Respiratory activities were higher in heart as compared with liver (as was Pal-CoA oxidation), suggesting more mitochondria per $\mathrm{g}$ tissue in the heart.

\section{PAL-COA OXIDATION IN ANIMALS FED HF AND LF DIETS}

Pal-CoA oxidation rates in the presence of excess ADP and carnitine were measured in heart and liver homogenates of littermates fed HF vs. LF diet. There was no significant difference (Student's $t$-test) between the HF and LF groups even at 10 days of

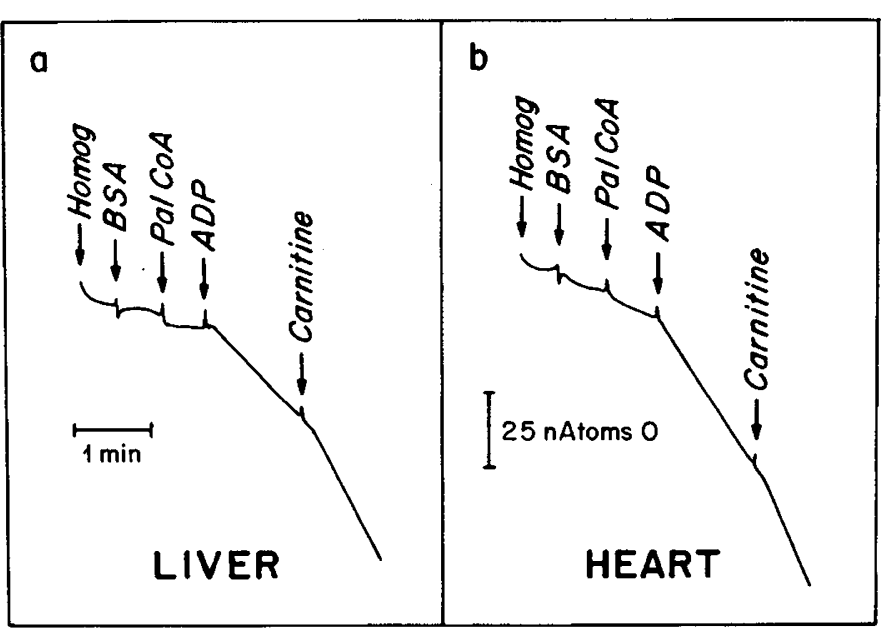

Fig. 1. Typical polarographic records of oxygen utilization in liver $(a)$ and heart $(b)$ homogenates with palmityl- $\mathrm{CoA}(\mathrm{Pal} \mathrm{CoA})$ as substrate. Hearts or livers from three 4-day-old normal animals were pooled and homogenates (Homog) prepared and assayed as described in the text. Sequential additions to the polarographic assays are indicated by arrows. $B S A$ : bovine serum albumin.
Table 1. Carnitine-dependent palmityl-COA oxidation in heart and liver homogenates of animals maintained on either high fat $(H F)$ or low fat $(L F)$ diet as described in text ${ }^{1}$

\begin{tabular}{|c|c|c|c|c|c|c|}
\hline & \multicolumn{2}{|c|}{4 days } & \multicolumn{2}{|c|}{7 days } & \multicolumn{2}{|c|}{10 days } \\
\hline & $\mathrm{HF}$ & LF & $\mathrm{HF}$ & LF & $\mathrm{HF}$ & LF \\
\hline \multicolumn{7}{|l|}{ Heart } \\
\hline Mean & 32.1 & 23.43 & 29.2 & 14.45 & 21.0 & 20.5 \\
\hline SEM & 3.76 & 5.79 & 4.61 & 1.38 & 8.50 & 8.11 \\
\hline$(n)$ & (4) & (3) & $(8)$ & (4) & $(2)$ & (3) \\
\hline \multicolumn{7}{|l|}{ Liver } \\
\hline Mean & 12.4 & 19.2 & 13.0 & 11.3 & 14.2 & 18.1 \\
\hline SEM & 1.05 & 1.8 & 1.52 & 1.68 & 2.95 & 4.35 \\
\hline$(n)$ & (4) & (3) & $(8)$ & $(6)$ & $(2)$ & (3) \\
\hline
\end{tabular}

${ }^{1}$ Values shown at each age are means and SEM for the number of individual animals in parentheses. Units are nanoatoms of oxygen per min per mg protein.

Table 2. Glutamate + malate-supported respiratory activity in heart and liver homogenates of animals maintained on either high fat $(H F)$ or low fat $(L F)$ diet as described in text ${ }^{1}$

\begin{tabular}{|c|c|c|c|c|c|c|}
\hline & \multicolumn{2}{|c|}{4 days } & \multicolumn{2}{|c|}{7 days } & \multicolumn{2}{|c|}{10 days } \\
\hline & $\mathrm{HF}$ & LF & $\mathrm{HF}$ & $\mathrm{LF}$ & $\mathrm{HF}$ & LF \\
\hline \multicolumn{7}{|l|}{ Heart } \\
\hline Mean & 64.2 & 60.2 & 82.1 & 55.4 & 49.5 & 58.6 \\
\hline SEM & 5.23 & 5.12 & 11.0 & 11.2 & 15.45 & 11.24 \\
\hline$(n)$ & (4) & (3) & $(8)$ & (4) & (3) & (3) \\
\hline \multicolumn{7}{|l|}{ Liver } \\
\hline Mean & 20.7 & 36.0 & 23.0 & 26.3 & 13.5 & 26.4 \\
\hline SEM & 1.62 & 6.75 & 1.50 & 1.91 & 4.78 & 6.41 \\
\hline$(n)$ & (3) & (3) & (8) & (6) & (3) & (3) \\
\hline
\end{tabular}

${ }^{1}$ Values shown at each age are means and SEM for the number of individual animals in parentheses. Units are nanoatoms of oxygen per min per mg protein.

age (Table 3). Pal-CoA oxidation in both groups was carnitine dependent, higher in heart than in liver, and was in general the same as that of mother-fed animals.

\section{PAL-COA OXIDATION RELATIVE TO CELLULAR RESPIRATION}

Because there was considerable variation in Pal-CoA oxidation rates from one animal to another, the results were re-examined in relation to other indices of mitochondrial respiration in each homogenate. Since FAO is localized in mitochondria, normalizing the data also made it possible to distinguish whether Pal-CoA oxidation was specifically increased or decreased over other mitochondrial functions.

The rates of $\mathrm{Pal}-\mathrm{CoA}$ oxidation normalized with respect to glutamate + malate respiratory activity are shown in Figure 2 as a function of age. Similarly, Pal-CoA oxidation relative to cytochrome oxidase activity is shown in Figure 3. Again no differences were apparent between $\mathrm{HF}$ and LF groups, and the values observed were generally similar to those for normal mother-fed pups (not shown). It is interesting that the ratio of Pal-CoA oxidation rates to respiratory activity is approximately the same in both heart and liver. This suggests that although there are 2- to 3 -fold more mitochondria in heart than in liver, the capacity for Pal-CoA oxidation per unit of mitochondria is about equal in both tissues. 
Table 3. Cytochrome oxidase activity in heart and liver homogenates of animals maintained on either high fat $(\mathrm{HF})$ or low fat $(L F)$ diet as described in text ${ }^{1}$

\begin{tabular}{|c|c|c|c|c|c|c|}
\hline & \multicolumn{2}{|c|}{4 days } & \multicolumn{2}{|c|}{7 days } & \multicolumn{2}{|c|}{10 days } \\
\hline & $\mathrm{HF}$ & LF & $\mathrm{HF}$ & LF & $\mathrm{HF}$ & LF \\
\hline \multicolumn{7}{|l|}{ Heart } \\
\hline Mean & 179.1 & 143.3 & 221.4 & 207.0 & 129.6 & 172.8 \\
\hline SEM & 13.6 & 26.3 & 17.8 & 48.8 & 19.4 & 24.0 \\
\hline$(n)$ & $(4)$ & (3) & $(8)$ & $(4)$ & (3) & (3) \\
\hline \multicolumn{7}{|l|}{ Liver } \\
\hline Mean & 84.5 & 111.6 & 72.7 & 71.0 & 64.7 & 55.3 \\
\hline SEM & 6.0 & 11.3 & 5.0 & 6.2 & & 13.2 \\
\hline$(n)$ & (4) & (3) & (8) & (6) & (2) & (3) \\
\hline
\end{tabular}

' Values shown at each age are means and SEM for the number of individual animals noted in parentheses. Units are nanoatoms of oxygen per min per mg protein.

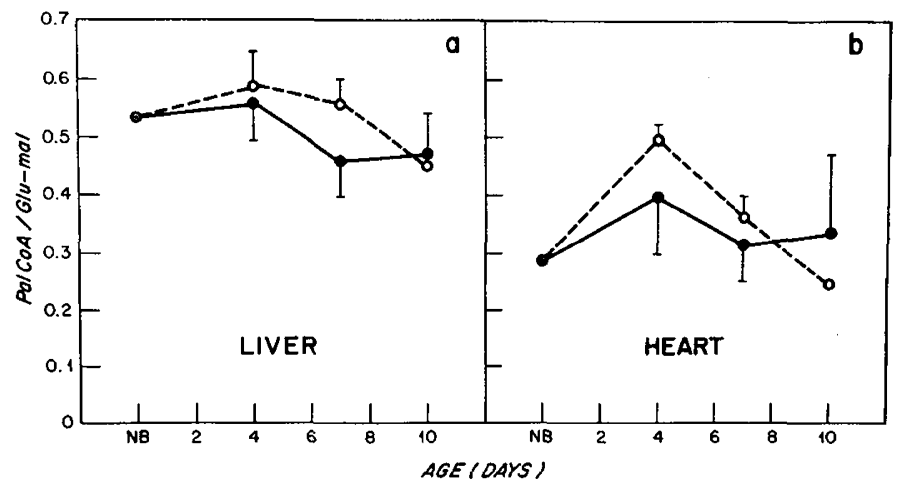

Fig. 2. Palmityl-CoA ( $P a l \mathrm{Co} A$ ) oxidation relative to glutamate + malate (Glu-mal) oxidation as a function of age in animals maintained on either a high fat $\left(\mathrm{O}_{-}-\mathrm{O}\right)$ or low fat (-C) diet. For each homogenate of liver $(a)$ or heart $(b)$, the rate of Pal CoA oxidation was divided by the rate of Glu-mal oxidation determined in the same sample. The normalized values ( $\mathrm{Pal} \mathrm{CoA} / \mathrm{Glu}$-mal) for individual animals were then averaged for each age. The bars represent 1 SEM for means where $n>2$.

\section{DISCUSSION}

No evidence was found to support the suggestion that the ability to oxidize fatty acids is influenced by the proportion of lipid in the postnatal diet (17). To our knowledge, this report is the first attempt to specifically test that hypothesis in a direct way. No difference was found in carnitine-dependent Pal-CoA oxidation rates in heart or liver homogenates from animals maintained on HF (78\% total calories as lipid) when compared with animals fed a LF diet (14\% total calories as lipid). Neither was there any effect of diet on rates of glutamate + malate oxidation or on cytochrome oxidase activity.

A composite summary of the enzymatic steps required for long chain FAO is shown in Figure 4. In order to reach intramitochondrial sites of $\beta$-oxidation, long chain fatty acids (e.g., palmitate) are first activated to the acylcoenzyme A derivative, then changed to an acylcarnitine by carnitine palmityltransferase A (localized on the outer surface of the inner mitochondrial membrane) (9). The acylcarnitine derivative traverses the inner membrane, probably via translocase mediated exchange diffusion with carnitine (14), and is converted back to the acyl coenzyme A derivative by carnitine palmityltransferase B (localized on the inner surface of the inner mitochondrial membrane) (9). The acyl coenzyme A derivative is then oxidized by $\beta$-oxidation to two carbon fragments (acetyl coenzyme A) which can enter the Krebs cycle. Final oxidation of the reducing equivalents so produced occurs in the respiratory chain. It is possible that overall rates of FAO could be controlled at any of these several required steps. Considerable evidence points to carnitine palmityltransferase $A$ as the ratelimiting step in adult animals $(6,12,16)$, although there is some disagreement about the perinatal role of carnitine palmityltransferase $(5,21)$

By studying the maximum rate of $\mathrm{Pal}-\mathrm{CoA}$ plus carnitine oxidation, any change in a rate-limiting step beyond acyl activation would have been detected. Since no difference was observed between animals fed a HF diet and those fed a LF diet, it must be concluded that large differences in the proportion of lipid in the postnatal diet do not influence the capacity to oxidize Pal-CoA. Since lipid calories in the $\mathrm{HF}$ diet were balanced against protein in the LF diet (3), this study also suggests that large differences in the amount of dietary protein (11\% vs. $57 \%$ of the total calories) do not affect rates of FAO.

As the study was nearing completion, it was noted that rabbit milk is somewhat atypical in its fatty acid composition, being enriched in short chain fatty acids (15). It is important, therefore, to continue this work, modifying the HF diet to include more of the short chain fatty acids, and using those acids as substrates in the biochemical assays before any general conclusions can be made. It will also be important to further modify the LF diet to completely eliminate any fat content, since small amounts may be sufficient for a regulatory role.

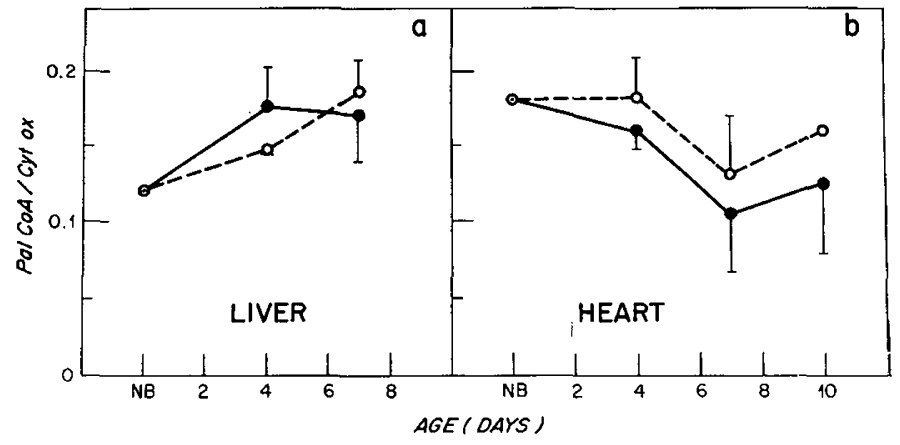

Fig. 3. Palmityl-CoA ( $P a l$ CoA) oxidation relative to cytochrome oxidase activity ( $C y t$ ox $)$ as a function of age in animals maintained on either a high fat $\left(\mathrm{O}-\mathrm{O}_{-}\right)$or low fat $(-\infty)$ ) diet. For each homogenate of liver $(a)$ or heart $(b)$, the rate of Pal CoA oxidation was divided by cytochrome oxidase activity determined in the same sample. The normalized values for individual animals were then averaged for each age. The bars represent 1 SEM for means where $n>2$.

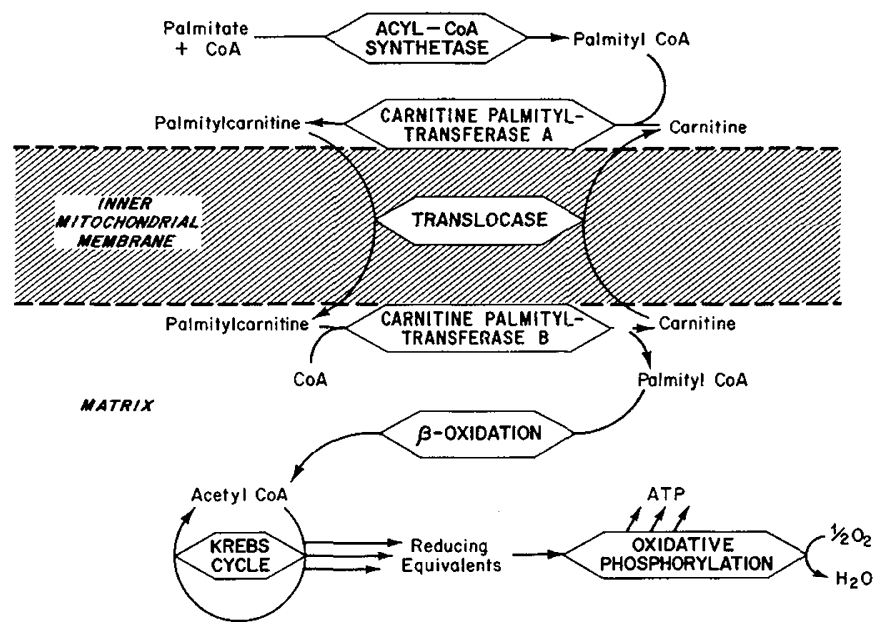

Fig. 4. Scheme to show enzymatic pathway of long chain fatty acid oxidation. See text for explanation. 
SUMMARY

Rabbit pups were maintained from birth either on a high fat, low protein diet or on a low fat, high protein diet for as long as 10 days. Rates of palmityl coenzyme A oxidation, glutamate + malate-supported respiration, and cytochrome oxidase activity in heart and liver homogenates were the same in both groups and similar in all respects to rates observed in mother-fed animals. In view of these findings, the hypothesis that the amount of lipid in the postnatal diet influences the ability to oxidize long chain fatty acids must be re-evaluated. It seems likely that other perinatal stimuli may be more important than diet in regulating oxidative energy metabolism to ensure survival during this critical transition period.

\section{REFERENCES AND NOTES}

1. Aas, M., and Daae, L. N.: Fatty acid activation and acyl transfer in organs from rats in different nutritional states. Biochim. Biophys. Acta, 239: 208 (1971).

2. Aprille, J. R., and Rulfs, J.: A convenient neonatal model for developmental studies requiring artificial diets. Biol. Neonate (In press.)

3. Aprille, J. R., and Rulfs, J.: Dietary lipid and postnatal development. I. A model for neonatal studies requiring high and low fat diets from birth. Pediat. Res. 10: 978 (1976).

4. Augenfeld, J., and Fritz, I.: Carnitine palmityltransferase activity in fatty acid oxidation by livers from fetal and neonatal rats. Can. J. Biochem., 48: 288 (1970).

5. Bieber, L. L., Markwell, M. A. K., Blair, M., and Helmrath, T. A.: Studies on the development of carnitine palmitoyltransferase and fatty acid oxidation in liver mitochondria of neonatal pigs. Biochim. Biophys. Acta, 326: 145 (1973).

6. Bremer, J., and Norum, K. R.: Palmityl CoA:carnitine O-palmityltransferase in the mitochondrial oxidation of palmityl CoA. Europ. J. Biochem., l: 427 (1967).

7. Breuer, E., Barta, E., Zlatos, L., and Pappora, E.: Developmental changes of myocardial metabolism. II. Myocardial metabolism of fatty acids in the early postnatal period of dogs. Biol. Neonat., 12: 54 (1968).

8. Chen, R. F.: Removal of fatty acids from serum albumin by charcoal treatment. J. Biol. Chem., 242: 173 (1967)

Copyright $\odot 1976$ International Pediatric Research Foundation, Inc.
9. Hoppel, C. L., and Tomec, R. J.: Carnitine palmityltransferase: Location of two enzymatic activities in rat liver mitochondria. J. Biol. Chem., 247: 832 (1972).

10. Lockwood, E., and Bailey, E.: Fatty acid utilization during development of the rat. Biochem. J., 120: 49 (1970).

11. Lowry, O. H., Rosebrough, N. J., Farr, A. J., and Randall, R. J.: Protein measurement with Folin phenol reagent. J. Biol. Chem., 193: 265 (1951).

12. McGarry, J. D., Meier, J. M., and Foster, D. W.: The effects of starvation and refeeding on carbohydrate and lipid metabolism in vivo in the perfused rat liver. J. Biol. Chem., 248: 270 (1973).

13. Novak, M., Penn-Walker, D., and Monkus, E. F.: Oxidation of fatty acids by mitochondria obtained from newborn subcutaneous (white) adipose tissue. Biol. Neonate, 25: 95 (1975).

14. Pande, S. V.: A mitochondrial carnitine acylcarnitine translocase system. Proc. Nat. Acad. Sci. U.S.A., 72: 883 (1975).

15. Scow, R. O., Mendelson, C. R., Zinder, O., Hamesh, M., and BlanchetteMackie, E. J.: Role of lipoprotein lipase in the delivery of dietary fatty acids to lactating mammary tissue. In: C. Galli, G. Jacini, and A. Pecile: Dietary Lipids and Postnatal Development (Raven Press, New York, 1973).

16. Shephered, O., Yates, D. W., and Garland, P. B.: The rate-limiting step in the oxidation of palmitate or palmityl-coenzyme $\mathrm{A}$ by rat-liver mitochondria. Biochem. J., 98: 3c (1966).

17. Warshaw, J. B.: Cellular energy metabolism during fetal development. IV. Fatty acid activation, acyl transfer and fatty acid oxidation during development of the chick and rat. Develop.Biol., 28: 537 (1972).

18. Warshaw, J. B., and Terry, M. L.: Cellular energy metabolism during fetal development. II. Fatty acid oxidation by the developing heart. J. Cell Biol., 44: $354(1970)$.

19. Widdowson, E.: Changes in the composition of the body at birth and their bearing on function and food requirements. In: J. Jonxis, $\mathrm{H}$. Visser, and J. Troelstra: Nutritia Symposium on the Adaptation of the Newborn Infant to Extrauterine Life (Stenfert Kroese N.V., Leyden, 1964)

20. Wittels, B., and Bressler, R.: Lipid metabolism in the newborn heart. J. Clin. Invest., 44: 1639 (1965).

21. Wood, J. M.: Carnitine palmityltransferase in neonatal and adult heart and liver mitochondria. J. Biol. Chem., 250: 3062 (1975).

22. The technical assistance of Jill Rulfs is gratefully acknowledged

23. This study was supported by grants from the United States Public Health Service (NIH HD08600) and the Charles H. Hood Foundation.

24. Requests for reprints should be addressed to: J. R. Aprille, Ph.D., Shriner's Burns Institute at the Massachusetts General Hospital, 50 Blossom St., Boston, Mass. 02114 (USA).

25. Accepted for publication June $28,1976$.
Chemotaxis lysosomal hydrolases mannosidosis $\alpha$-mannosidosis

neutrophil

$\mathrm{Zn}$-dependent enzymes

\title{
Mannosidosis: Clinical, Morphologic, Immunologic, and Biochemical Studies
}

\author{
ROBERT J. DESNICK, ${ }^{(58)}$ HARVEY L. SHARP, GREGORY A. GRABOWSKI, RICHARD D. \\ BRUNNING, PAUL G. QUIE, JOO H. SUNG, ROBERT J. GORLIN, AND JUSTUS U. IKONNE
}

Departments of Pediatrics, Genetics and Cell Biology, Laboratory Medicine and Pathology, Neurology, Oral Pathology, and the Dight Institute for Human Genetics, University of Minnesota, Minneapolis, Minnesota, USA

\section{Extract}

The primary metabolic defect in mannosidosis is the deficiency of the acidic $\alpha$-mannosidase $A$ and $B$ activities which results in the lysosomal accumulation of mannose-rich substrates. Our studies demonstrate that the enzymatic diagnosis of suspect homozygotes can be made reliably using plasma, isolated leukocytes, or cultured skin fibroblasts assayed carefully at the appropriate acidic $\mathrm{pH}$.

Immunologic studies of a mannosidosis homozygote revealed significant abnormalities of neutrophil function; these included a depressed chemotactic responsiveness and impaired phagocytosis of bacteria. Lymphocyte transformation studies showed a $20 \%$ of normal response to purified phytohemagglutinin and a $25 \%$ of normal response to concanavalin $A$.

Three major components of $\alpha$-mannosidase activity in normal human liver were resolved by ion exchange chromatography on DEAE-cellulose and electrophoresis on cellulose acetate gels. Electrophoresis of the liver extract from homozygote $I$ with mannosidosis revealed only one band of activity which coelectrophoresed with the $\alpha$-mannosidase $C$ isozyme partially purified from normal liver. However, ion exchange chromatography revealed the presence of residual hepatic acidic activities; the residual $A$ 